\title{
A Review on the Resilient Response of Unsaturated Subgrade Soils
}

\author{
Xuanxuan Chu (D) \\ Nottingham Transportation Engineering Centre, Faculty of Engineering, University of Nottingham, Nottingham NG7 2RD, UK \\ Correspondence should be addressed to Xuanxuan Chu; chuxuanxuan@126.com
}

Received 11 November 2019; Revised 9 January 2020; Accepted 22 January 2020; Published 27 February 2020

Academic Editor: Sanjay Nimbalkar

Copyright (c) 2020 Xuanxuan Chu. This is an open access article distributed under the Creative Commons Attribution License, which permits unrestricted use, distribution, and reproduction in any medium, provided the original work is properly cited.

Considering the great contribution of subgrade modulus to the overall performance of roads or railways, it is crucial to provide the best prediction of resilient modulus for their foundations. Incorporating the seasonal variation of moisture content, the resilient modulus variation of unsaturated soils will be accurately predicted. This paper aims to introduce and discuss the knowledge about resilient response of unsaturated soils and emphasize the effects of humidity. A literature review on resilient response of unsaturated soils is presented based on the previous studies. The affecting factors (i.e., wetting and drying, moisture content, and matric suction) were discussed. The prediction model development of the resilient response of unsaturated soils was presented. The limitations and advantages of the model were analyzed and compared. It reveals that the current models were limited regarding stress conditions, moisture content, matric suction, and soil types, and further studies are still needed to achieve a better understanding of resilient response of unsaturated soils.

\section{Introduction}

Subjected to moving loads, the underlying soil layers may exhibit a resilient (recoverable) and a plastic (irrecoverable or permanent) deformation. Figure 1 illustrates the stressstrain behaviour in a simple way [1]. Consequently, the infrastructure may undergo distresses that undermine the overall performance. Regarding road pavements, various distresses have been investigated, e.g., cracking (fatigue, block, edge, reflection, longitudinal, and transverse), patching (patch deterioration, and potholes), surface deformation (rutting and shoving), surface defects (bleeding, polished aggregate, and ravelling), and miscellaneous distresses (lane-to-shoulder drop-off, water bleeding, and pumping) [2]. In terms of the two major issues, fatigue cracking of bound layers may derive from resilient deformation of subgrade soils in the foundation, whereas excessive rutting may be attributed to plastic deformation. Therefore, it is critical that the resilient response of foundation soils under moving loads should be comprehensively revealed [1], providing further reference for more rational foundation design.

To reflecting the stress-strain behaviour (i.e., resilient response) of subgrade soils under normal cyclic traffic loading, $M_{r}$ of subgrade soils was introduced by American Association of State Highway and Transportation Officials (AASHTO) [3] as a more rational soil property than the soil support value or modulus of subgrade reaction [4] and therefore is widely employed to estimate transient soil deformation under repeated traffic loads. As a significant stiffness parameter to demonstrate the resilient behaviour, the resilient modulus $M_{r}$ is mathematically defined as the ratio of repeated deviator stress $q$ to axial recoverable strain (i.e., resilient strain) $\varepsilon_{r}$ [5] as follows:

$$
M_{r}=\frac{q}{\varepsilon_{r}} \text {. }
$$

Considering the great contribution of subgrade modulus to the overall performance of the roads or railways, it is crucial to provide the best prediction of resilient modulus for the road and railway foundations. Many efforts have been dedicated to the studies on resilient response of saturated soils, e.g., [6-8]. Various models were developed to demonstrate the nonlinear stress-strain behaviour of saturated subgrade soils by incorporating soil physical properties (e.g., moisture content and dry density) and stress state variables (e.g., deviator stress, confining stress, bulk stress, and shear stress). These models include the $k-\theta$ model [9], the 


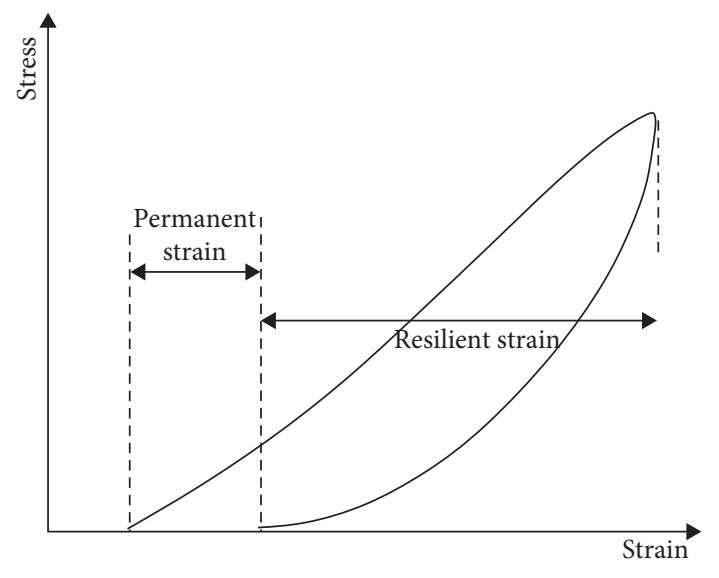

FIGURE 1: Simplified stress-strain behaviour in granular materials during one loading cycle [1].

deviator stress model [6], the Uzan model [10], the Universal Model [11], and the model by Mechanistic-Empirical Pavement Design Guide (MEPDG) [12], and so on. Some reviews on the studies of saturated soils were also proposed, based on the previous references, e.g., $[1,13]$, to demonstrate the state of knowledge about resilient response. Thus, a better understanding may have been achieved about the resilient response of saturated soils.

In practice, the maximization of density is crucial in developing the full-strength potential of the material. In the condition of optimum moisture content (OMC), the easiest compaction can be performed, and the maximum density will be acquired [14]. Thus, to achieve the maximum dry density (MDD) of subgrade soils, construction specifications universally require that the soils be compacted at (or near) OMC in practice, and therefore all placed and many in-situ subgrade soils should be regarded as materials in an unsaturated state above the water table $[4,15]$ or in a near-saturated condition. Due to the environmental conditions (e.g., wetting and drying, freezing and thawing, and precipitation), unsaturated soils will be subjected to seasonal variations in moisture content [15-18]. Consequently, it will be complicated to thoroughly understand the nature of resilient response of unsaturated soils. Regarding the in-situ conditions, the unsaturated soils have raised increasing concerns among scholars and engineers. In this circumstance, further studies should still be performed to thoroughly explore the nature of the resilient modulus of unsaturated soils.

With the concern to unsaturated soils, an increasing number of efforts were made (e.g., [16, 19-24]) to predict the resilient behaviour of subgrade soils, which are more accurate than those generally referring to unsaturated soils as saturated soils due to simplicity. The proposed experimental and theoretical methods broaden the knowledge of unsaturated soil in predicting the response. Thus, based on the current knowledge about the resilient response of unsaturated soils, a review is necessary and significant to demonstrate a better understanding of resilient response of unsaturated soils.

This paper aims to introduce and discuss the knowledge about resilient response of unsaturated soils. A selective literature review on resilient response of unsaturated soils is presented based on the previous studies. The affecting factors and prediction model development of the resilient response of unsaturated soils are investigated, respectively. The review could be inevitably limited by covering the two aspects, while it may possibly provide reference for the foundation design and construction incorporating unsaturated soils.

\section{Factors Affecting Resilient Response}

Based on previous studies, the mechanical properties of $\mathrm{road} / \mathrm{railway}$ trackbed foundations (e.g., resilient response) were found to depend on various variables. For example, great concerns were raised about the resilient modulus in previous studies. The studies indicated that the resilient modulus was influenced by moisture content, matric suction, external stress, number of load repetitions, stress state, wetting and drying history, and soil type [13, 21, 25-28].

Compared with saturated soils, the unsaturated subgrade soils contain matric suction that will affect the mechanical response of the soil foundations. Matric suction has been considered as an important stress variable in investigating the effects of moisture content on the mechanical behaviour of unsaturated soils. It is widely recognized that matric suction mainly includes two components, i.e., matric and osmotic suctions [29-31]. The relationship can be expressed as

$$
\psi=\left(u_{a}-u_{w}\right)+\pi
$$

where $\psi$ is the total suction, $\left(u_{a}-u_{w}\right)$ is matric suction, $\pi$ is osmotic suction, $u_{a}$ is pore-air pressure, and $u_{w}$ is pore water pressure. The total suction indicates the free energy of the soil water, while matric and osmotic suctions are the components of the free energy. Khoury et al. [24] demonstrated that the variations in the resilient modulus were not induced by osmotic suction. In general, matric suction is mainly considered to analyze the soil response concerning the unsaturated soil.

Overall, the impact factors affecting resilient behaviour can be summarized as stress state (matric suction, total, confining and deviator stress), soil physical state (moisture content, dry density, and soil type/structure (fabric)), loading condition (magnitude of load and number of load repetitions) [32], and compaction (both density and compaction methods). Especially, the water effects on the subsurface structures were presented and discussed by many researchers, e.g., Drumm et al. [15], Khoury et al. [24], Miller et al. [26], Kim et al. [33], Nuth et al. [34], Dawson [35], and Coronado et al. [36]. Although there are a wide variety of studies available to discuss the effects of other factors on resilient response of soils (e.g., [1]), they are mainly centred on the saturated soils. In the review by Lekarp et al. [1], the effects of moisture content were presented based on pore water pressure, degree of saturation, and water table, whilst the gravimetric/volumetric moisture content itself was not involved. The hysteresis of the resilient modulus with moisture content and the effects of matric suction were not 
included for a better understanding of unsaturated soils. The effects of moisture on resilient response of subgrade are reflected in different ways including direct correlation, wetting and drying process, and matric suction. Specifically, matric suction, as an important state variable to unsaturated soils, will be discussed separately.

2.1. Moisture Content. Attributed to precipitation, capillary action, flooding and water table variation, and so on, the moisture content in the subgrade may vary. The existing water will induce positive pore water pressure, which can reduce the load carried by the soil particles. It may also cause weathering and reduce the friction resistance. Consequently, the structural bearing capacity could decrease, and the water would further accelerate the deterioration of foundations in pavement and railway track structures under repeated traffic loading, and therefore endanger the stability and reliability of transport.

2.1.1. Direct Correlation. Among the affecting factors, moisture content is well known to have significant effects on the deformation behaviour of unbound granular materials. It is analyzed that the modulus would decrease with higher moisture content, while the permanent deformation and Poisson's ratio increased progressively [37], e.g., with the moisture content rising by $2 \%$, the resilient modulus of cohesive soils reduced significantly up to 4 times [38], and especially, at high degree of saturation, unbound granular materials showed significant decrease in the resilient modulus with the increasing degree of saturation. Saevarsdottir and Erlingsson [39] conducted accelerated pavement tests with a heavy vehicle simulator, and the effects on the responses of the structure were measured with the decreased resilient modulus and increased rate of accumulation of permanent deformation as the water table was raised to increase moisture content. The bottom part of the subbase presented the largest increase in resilient strain by $53 \%$ with the increase in that of base and the top $30 \mathrm{~cm}$ of subgrade by $15 \%$ and about $20 \%$, respectively.

2.1.2. Wetting and Drying. Wetting and drying was also found to affect the resilient modulus [28]. However, due to the inconsistency or variable nature of subgrade strength [40], the values of $M_{r}$ do not continuously decline in the whole wetting cycle [41]. Rahman and Erlingsson [41] found that $M_{r}$ showed an increasing trend with moisture rising to the optimum due to the development of suction, while the values decreased above the optimum since the materials would develop excess pore water pressure at higher degree of saturation, which is in good agreement with the findings of Dawson et al. [37]. It could also be likely attributed to improved packing rearrangement of soil particles [42] due to water, and the postcompaction was enhanced as well. It was also confirmed that compaction atOMC could play a positive role in improving the strength of foundation.
2.1.3. Cyclic Wetting-Drying. Due to climatic changes (e.g., alternating periods of rainfall and draught), soil is also subjected to repeated wetting-drying cycles. Cyclic wettingdrying process will lead to the buildup and breakdown of soil particles and bear the responsible for a continuous increase in the stability of aggregates $[43,44]$. The soil may be more susceptible to yield and thus exhibit a softening behaviour due to the irreversible swelling or increase in degree of saturation from the wetting-drying cycles [45]. Tang et al. [46] found that the cyclic wetting-drying seemed to slightly increase the soil stiffness in the case of lime-treated soils and decrease the soil stiffness in the case of untreated soils. Based on the Meridian limestone aggregate stabilized with cement kiln dust, it is found out that the resilient modulus showed significant decrease as the number of wetting/drying cycles increased to 8 , beyond which the resilient modulus decreased only slightly [47]. In addition, it reveals that the resilient modulus of the soil compacted at OMC may decrease up to four times by wetting and drying cycles [48].

2.1.4. Hysteretic Behaviour. Furthermore, moisture content exhibited a hysteretic behaviour in the relationship with resilient modulus due to the wetting and drying processes [16], and $M_{r}$ showed higher values for drying cycle at the same moisture content than on the wetting cycle. Khoury et al. [18] also found the resilient modulus-moisture content relationships caused by drying presented higher values than by wetting. With regard to the nonlinearity, increasing moisture content show few effects on it [37]. According to the acquired soil water characteristic curve (SWCC), the similar trend was also measured in matric suction, as presented in Figure 2.

2.2. Matric Suction. Soil is commonly assumed to be saturated without considering the suction effects, and zero suction is taken as the saturation state [50]. Regarding the unsaturated state of soil, with the development of soil mechanics, matric suction has been considered as an important stress variable in investigating the effects of moisture content on the mechanical behaviour of unsaturated soils in pavement structures. It is widely recognized that soil suction mainly consists of the capillary and adsorptive potentials, i.e., matric and osmotic suction [29-31]. The relationship can be expressed as shown in Eq. (2). The total suction indicates the free energy of the soil water, while matric and osmotic suctions are the components of the free energy.

As Leong and Abuel-Naga [51] demonstrated, matric suction $\left(u_{a}-u_{w}\right)$ is associated with the capillary effects, while osmotic suction depends on the salt content of the pore water. The strong correlation has been revealed between matric suction and resilient modulus [16]. Khoury et al. [24] demonstrated that the variations in the resilient modulus were not induced by osmotic suction. Based on the analysis of the experimental data, it was found that the resilient modulus correlated better with matric suction than with total suction [4], as illustrated in Figure 3. Furthermore, based on the previous studies, the effects of matric suction should be mainly incorporated in the analysis on the 


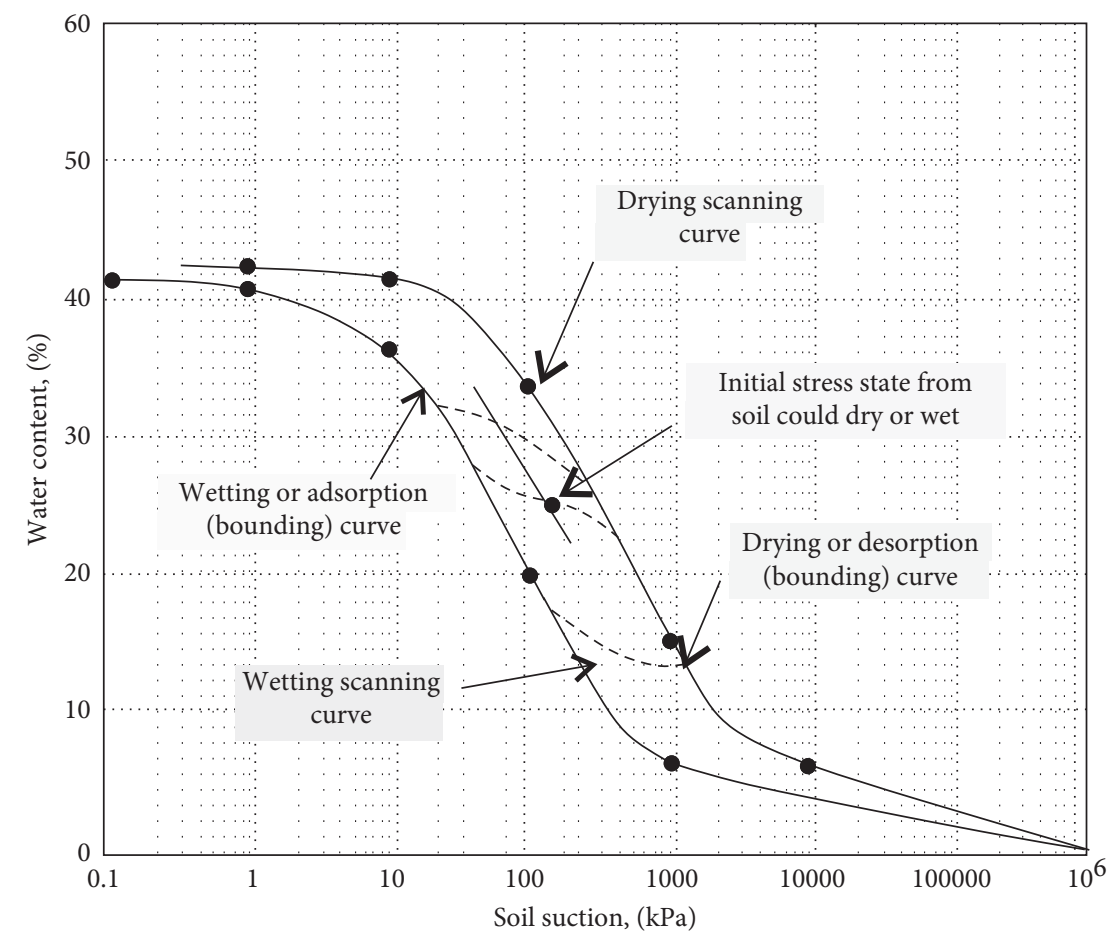

FIgURE 2: Relationship of initial stress state to hysteresis loops of SWCC (from [49]).

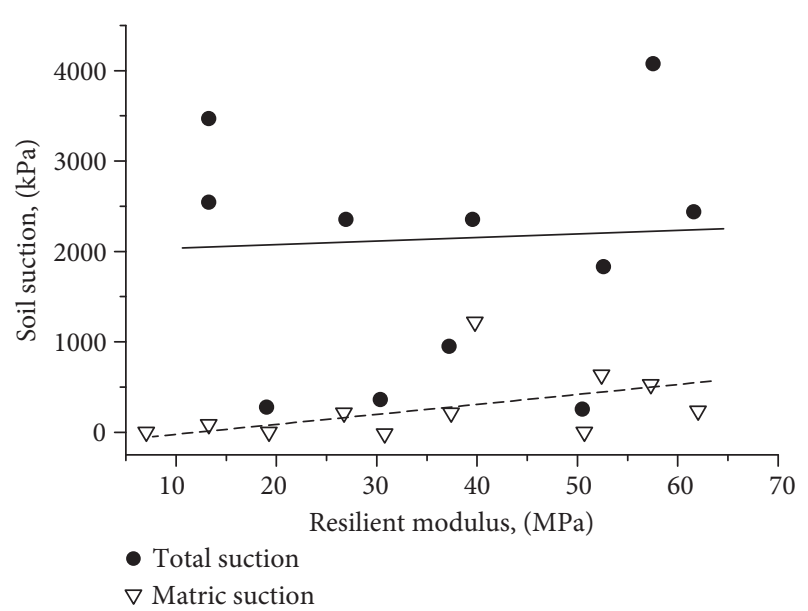

Figure 3: Illustration of the relationship between resilient modulus and matric suction for A-7-5 and A-7-6 soils $\left(\sigma_{d}=103 \mathrm{kPa}\right.$; $\left.\sigma_{3}=21 \mathrm{kPa}\right)$ (from [4]).

behaviour of partially saturated soil in preference to the effects of total and osmotic suctions.

Matric suction affects the mechanical behaviour of unsaturated soils as a fundamental stress variable, and the effects vary with stress states. Matric suction generates capillary interparticle forces normal to particle contacts, and it plays a more complicated role compared with the pore pressure or mean stress [50]. The roles of the matric suction in the mechanical response of the soils can be revealed from two aspects, i.e., affecting the stress existing in the soil particle with pore water pressure and exerting a force on the particle to reinforce the bonding. With respect to the two mechanisms, the effects of suction on the response also rely on the saturation state of the soil $[52,53]$. When considering suction effects, the fabric measure of pore fluid in the soil should also be involved to quantify the distribution of pore pressures [54].

Referring to resilient modulus, it showed a nonlinear increasing trend with a lower matric suction (e.g., $[4,13,17,18,31,53,55]$, whilst the same trend may not be recognized at higher suction levels. It may be induced by the more effective contribution of soil suction on wetted contacted area of soil particles within the low suction levels [56], although the limited wetted contacted area at higher suction levels impaired the effect of suction. Ng et al. [27] found that the resilient modulus increased significantly with suction due to the presence of water tension, and it increased by up to one order of magnitude with suction rising from 0 to $250 \mathrm{kPa}$ at a cyclic stress of $30 \mathrm{kPa}$, as can be seen from Figure 4 .

Plenty of studies have been performed on the prediction model of the resilient modulus of subgrade soils, and more model parameters were considered, e.g., confining stress, bulk stress, or dry density [4]. Since the matric suction can reflect effects of the seasonal variation of moisture content on the resilient modulus under in-situ conditions, the model based on the resilient modulus will be expected to be more reliable through incorporating matric suction. Particularly, at a low moisture content, the resilient modulus is dominated by the significant matric suction for the soil. It may benefit the foundation design with a better understanding and measurement of matric suction.

\section{Models Based on Resilient Modulus}

3.1. Stress Principles. Due tovarious pore water pressures and matric suction conditions in saturated/unsaturated 


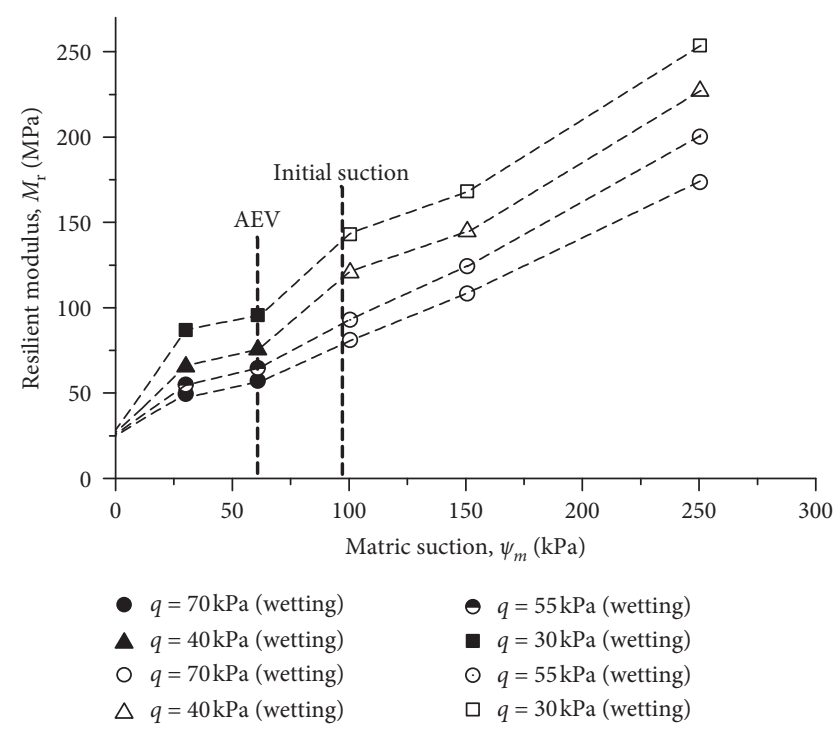

FIGURE 4: Influence of suction on resilient modulus $\left(\psi_{m}=0,30\right.$, and 60 in series 1 tests; $\psi_{m}=100,150$, and 250 in series 2 tests. $q$ is the cyclic stress.) (from [27]).

states, the subgrade soil will also exhibit different stress conditions. In order to accurately investigate the mechanical response of the soil, the stress state should be obtained.

In the saturated state, the mechanical state of soil can be described by a stress state variable, i.e., effective normal stress, $\sigma_{i j}^{\prime}$, which, according to the principle of effective stress [57], can be expressed as

$$
\sigma_{i j}^{\prime}=\sigma_{i j}-u_{w} \delta_{i j}
$$

where $\sigma_{i j}$ is total normal stress and $u_{w}$ is the pore water pressure, which is generally positive or zero for the saturated soil. It allows recognition of the stress components carried by the soil and by the pore water. [58]

In the unsaturated state, the effective stress is defined as

$$
\sigma_{i j}^{\prime}=\sigma_{i j}^{n e t}+\chi \psi_{m} \delta_{i j}
$$

where $\sigma_{i j}^{\text {net }}$ is the net stress, $\psi_{m}$ is the matric suction (i.e., $\left.u_{a}-u_{w}\right), \delta_{i j}$ is the Kronecker delta and $\chi$ is effective stress parameter thought to be a function of degree of saturation ( $\chi=0$ for dry soils, $\chi=1$ for saturated soils), defined as

$$
\chi=\left[\frac{\left(u_{a}-u_{w}\right)_{b}}{u_{a}-u_{w}}\right]^{0.55},
$$

where $\left(u_{a}-u_{w}\right)_{b}$ is the air entry of the soil (or matric suction where air starts to enter the largest pores in the soil). $\chi$ is also found to depend on the material state and stress path. However, no unique relationship is found between $\chi$ and the degree of saturation [59], and, instead, $\chi$ is strongly related to the soil structure [60]. As a material parameter, $\chi$ is not suitable for the description of stress since the variables used should be independent of material properties [61].

Zero suction was commonly regarded and accepted as the equivalent to saturated states despite its shortcomings, i.e., the hysteretic suction levels were ignored that correspond to full saturation during drying and wetting, respectively, and a continuous treatment between positive and negative pore water pressure was not displayed. As to atmospheric pressure and the suction, they may be treated as zero and a negative pore water pressure for all saturated state as a better alternative, which will also provide a continuous transition between saturated and unsaturated states [50]. Bishop's effective stress exhibited several limitations, e.g., failure to explain the collapse behaviour during wetting of unsaturated soils [62] and the dependence of the represented stress space on the material states.

Considering all the limitations of effective stress principles, Fredlund and Morgenstern [61] defined the stress state by two independent nonadditive stresses, one described at the macroscopic scale $\left(\sigma_{i j}-u_{a} \delta_{i j}\right)$ and the other at the pore scale $\left(u_{a}-u_{w}\right)$. The effective stress is rewritten as

$$
\sigma_{i j}^{\prime}=\sigma_{i j}-u_{a} \delta_{i j}+\chi\left(u_{a}-u_{w}\right) \delta_{i j},
$$

where $\sigma_{i j}^{\prime}$ is also termed as quasi-effective stress, since it is not a true stress in the context of continuum mechanics [54]. The quasi-effective stress may be defined as

$$
\begin{aligned}
\sigma_{i j}^{\prime} & =-\frac{1}{V} \sum_{m=1}^{N^{p}} \sum_{\alpha=1}^{N^{m}} f_{j}^{m_{\alpha}} r_{i}^{m_{\alpha}}=\left(\sigma_{i j}-u_{a} \delta_{i j}\right)+\left(u_{a}-u_{w}\right) F_{i j}=\sigma_{i j}^{n e t}+s F_{i j}, \\
F_{i j} & =S_{r} \delta_{i j}+\frac{1}{V}\left[\int_{\Gamma} x_{i} \lambda_{j} d \Gamma-\sum_{m=1}^{N^{p}} x_{i}^{c_{m}}\left(\int_{S_{w}^{m}} n_{j} d A+\int_{\Gamma^{m}} \lambda_{j} d \Gamma\right)\right] \\
& =S_{r} \delta_{i j}-\frac{1}{V} \sum_{m=1}^{N^{p}} x_{i}^{c_{m}} \int_{S_{w}^{m}} n_{j} d A+\frac{1}{V}\left[\int_{\Gamma} x_{i} \lambda_{j} d \Gamma-\sum_{m=1}^{N^{p}} x_{i}^{c_{m}} \int_{S_{w}^{m}} \lambda_{j} d \Gamma\right] \\
& \triangleq S_{r} \delta_{i j}+\xi_{i j}^{\prime}+\xi_{i j}^{\prime \prime},
\end{aligned}
$$

where $F_{i j}$ is a second-order tensor that characterises the effect of matric suction. Therefore, $\sigma_{i j}^{\prime}$ is a function of $F_{i j}$, and $F_{i j}$ is a measure of the tensorial nature of the pore fluid fabric in the soil. It is inadequate to describe the critical state of unsaturated soils only based on the continuum stress state (shear stress, net normal stress, and matric suction) and the soil volume [54].

3.2. Resilient Modulus Models. In view of the substantial contribution of the subgrade modulus to the overall performance of the roads or railways, it is significant to provide the best prediction of the resilient modulus for the roads and railway foundations. Various models based on the resilient modulus were developed to demonstrate the nonlinear stress-strain behaviour of the subgrade soils by incorporating soil physical properties (e.g., moisture content and dry density) and stress state variables (e.g., deviator stress, confining stress, bulk stress, and shear stress). Some commonly used models for saturated soil and discussions surrounding them are firstly presented as a reference to the development of models for unsaturated soil, e.g., $k-\theta$ model, deviator stress model, and Universal model, and then generally discussed. More models based on the resilient modulus (e.g., the model by Dunlap [63], Monismith et al. 
[9], Pezo [64], Garg and Thompson [65], and Tam and Brown [66]), Poisson's ratio (e.g., models by Hicks and Monismith [67] and Karasahin et al. [68]) and shear-volumetric approach (e.g., the contour model by Pappin [69] and Boyce model [70]) can be found in a study by Lekarp et al. [1] to model the stress-strain relationship. The models incorporating moisture content and matric suction will be mainly presented for the unsaturated soils.

(1) The $k-\theta$ model associating the resilient modulus with bulk stress was presented by Monismith, Seed, and Mitry [9] generally for granular soils as

$$
M_{r}=k_{1}\left(\frac{\theta}{p_{a}}\right)^{k_{2}},
$$

where $k_{1}$ and $k_{2}$ are regression parameters dependent on material types and soil physical properties; $\theta=\sigma_{1}+\sigma_{2}+\sigma_{3}\left(\sigma_{1}, \sigma_{2}\right.$, and $\sigma_{3}$ are the three principal stresses), i.e., bulk stress; $p_{a}$ is the atmospheric pressure.

It is widely used to analyze the stress dependence on material stress, whilst the $k-\theta$ model is not specifically accurate to describe the soil behaviour at various locations despite right below an applied load. When considering the use of finite element method or the assumption of simplified pavement structure, this model will induce more complication to pavement analysis [14]. Constant Poisson's ratio was assumed in this model, whilst Poisson's ratio was not constant and varied with applied stresses [11]. It is still insufficient to consider the effects of stresses only by the sum of principal stresses since the same value of $\theta$ may represent different stress states. This model did not summarize measured data well when shear stress was significant [10].

(2) The model proposed by Moossazadeh and Witczak [6], also known as the deviator stress model widely used to represent the resilient modulus of finegrained subgrade soils, was presented as

$$
M_{r}=k_{1}\left(\frac{\sigma_{d}}{p_{a}}\right)^{k_{2}},
$$

where $\sigma_{d}$ is the deviator stress, i.e., $\sigma_{1}-\sigma_{3}$.

Based on the deviator stress, $M_{r}$ could be easily estimated. A limitation of this model is that moisture conditions were not explicitly incorporated.

(3) The Universal model [71] incorporated the effect of both shear stress and bulk stress on $M_{r}$ as follows:

$$
M_{r}=k_{1} * p_{a}\left(\frac{\theta}{p_{a}}\right)^{k_{2}}\left(\frac{\tau_{\mathrm{oct}}}{p_{a}}\right)^{k_{3}},
$$

where $\tau_{\text {oct }}$ is the octahedral shear stress, i.e., $1 / 3 \sqrt{\left(\sigma_{1}-\sigma_{2}\right)^{2}+\left(\sigma_{2}-\sigma_{3}\right)^{2}+\left(\sigma_{1}-\sigma_{3}\right)^{2}}$.
Based on the studies, the Universal Model showed superior performance to the $k-\theta$ model. The Universal Model is recommended for use with cohesive soils if the model development data have various confining stress levels [72].

(4) Developed by Fredlund and Rahardjo [12], $M_{r}$ of unsaturated soils can be expressed as a function of three stress variables, i.e.,

$$
M_{r}=f\left[\left(\sigma_{3}-u_{a}\right),\left(u_{a}-u_{w}\right),\left(\sigma_{1}-\sigma_{3}\right)\right],
$$

where $u_{a}$ is the pore-air pressure and $\left(\sigma_{3}-u_{a}\right)$ is the net confining pressure.

The model provides a general idea for the relationship between the resilient modulus and stress variables (i.e., deviator stress, net confining stress, and matric suction). The effects of matric suction were gradually incorporated to predict the resilient modulus of unsaturated soils.

(5) A model was recommended in MEPDG [73] by AASHTO to demonstrate the effect of degree of saturation on $M_{r}$ :

$$
\log \frac{M_{r}}{M_{r, \mathrm{opt}}}=a+\frac{b-a}{1+e^{\ln (-b / a)+k_{4}\left(S-S_{\mathrm{opt}}\right)}},
$$

where $M_{r, \text { opt }}$ is the resilient modulus at OMC $\left(w_{\text {opt }}\right), a$ is the minimum of $\log \left(M_{r} / M_{r, \text { opt }}\right), b$ is the maximum of $\log \left(M_{r} / M_{r, \text { opt }}\right), k_{4}$ is the regression parameter associated with material properties, $S$ is the degree of saturation expressed as decimal, and $S_{\text {opt }}$ is the degree of saturation at $w_{\text {opt }}$ expressed as decimal.

This model takes a degree of saturation into account, so the water state will be involved. However, matric suction as the direct factor is not considered, and the hysteretic behaviour of $M_{r}$ with moisture content is not demonstrated [23].The $M_{r}$-moisture relationships vary with soil types, particularly with plasticity index (PI), e.g., low PI soils are less susceptible to moisture changes than soils with high PI [16] and the model may be exclusively applicable to some specific soil types.

(6) By incorporating the effective stress of unsaturated soils presented by Bishop [58], the model by AASHTO [3] is rewritten by Yang, Huang, and Tai [4], as follows:

$$
M_{r}=k_{1}\left(\sigma_{d}-u_{a}+\chi \psi_{m}\right)^{k_{2}}
$$

This model cannot address the effects of drying or combination of drying and wetting on $M_{r}$ values of subgrade soils [23].

(7) Based on the effective stress, the proposed model by Liang et al. [74] for partially saturated cohesive soils can be expressed as 


$$
M_{r}=k_{1} p_{a}\left(\frac{\theta+\chi \psi_{m}}{p_{a}}\right)^{k_{2}}\left(\frac{\tau_{\mathrm{oct}}}{p_{a}}+1\right)^{k_{3}}
$$

In this model, the matric suction is included, and the suction parameter $\chi$ is introduced. It also considers the effects of shear strain. However, the measurement of soil suction may induce complications to the model.

(8) As the variation of the Universal Model, a refined model was proposed by Cary and Zapata [55], as follows:

$$
\begin{aligned}
M_{r}= & k_{1} p_{a}\left(\frac{\theta_{\text {net }}-3 \Delta u_{w-\text { sat }}}{p_{a}}\right)^{k_{2}}\left(\frac{\tau_{\text {oct }}}{p_{a}}+1\right)^{k_{3}} \\
& \cdot\left(\frac{\psi_{m_{0}}-\Delta \psi_{m}}{p_{a}}+1\right)^{k_{5}},
\end{aligned}
$$

where $\theta_{\text {net }}$ represents net bulk stress, i.e., $\theta-3 u_{a}$, $\Delta u_{w-\text { sat }}$ is the buildup of pore water pressure under partially saturated conditions; $\psi_{m_{0}}$ is the initial soil matric suction and $\Delta \psi_{m}$ is the relative change in soil matric suction with respect to $\psi_{m_{0}}$; $k_{5}$ is the regression constant.

To obtain net bulk stress, pore-air pressure needs to be determined. Considering the variation of matric suction is beneficial, whilst the measurement of matric suction will induce more complexity to the prediction of $M_{r}$. During the repeated loading, buildup of pore water pressure could cause changes to the matric suction, which could also impair its accuracy.

(9) Based on the MEPDG [73] model, Khoury et al. [23] proposed two models to assess the $M_{r}$-moisture hysteretic behaviour of a subgrade soil along two different environmental paths. A revised model to predict $M_{r}$ incorporating the effects of moisture content along initial drying curve (IDC) and initial wetting curve (IWC), i.e.,

$$
\log \left(\frac{M_{r}}{M_{r, \mathrm{opt}}}\right)=a_{1}+\frac{b_{1}-a_{1}}{1+e^{\ln \left(-b_{1} / a_{1}\right)+k_{6} \times\left(w-w_{\mathrm{opt}}\right)}} .
$$

Through the statistical analysis, model parameters prove to be as follows: $a_{1}=-0.162, b_{1}=0.435$, and $k_{6}=0.803$, with a coefficient of determination $r^{2}=0.95$. The inner $M_{r}$-moisture curve (IMMC) was introduced to present the IDC and IWC as a whole, as shown in Figure 5.

The following equation was selected to analytically predict the $M_{r}$-moisture variation along the main drying curve-wetting- drying path (MDC-WDP):

$\log \left(\frac{M_{r}}{M_{r, \text { opt }}}\right)_{\text {MDC-WDP }}=a+\frac{b-a}{1+e^{k_{6} \times\left(w-w_{\mathrm{opt}}\right)}}$,

where $M_{r} / M_{r, \text { opt }}$ is resilient modulus ratio, $k_{6}$ is the regression parameter, and $\left(w-w_{\text {opt }}\right)$ is moisture

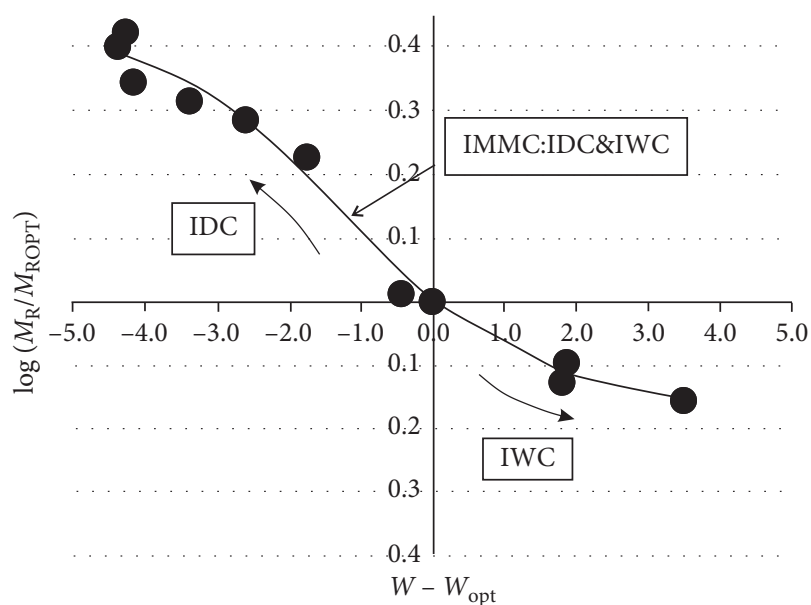

FIGURE 5: $M_{r}$-water relationship along the IDC and the IWC (i.e., IMMC) (from [23]).

content variation (\%). With the slope of IMMC and the resilient modulus along the IMMC at specific moisture content $\left(w-w_{\text {opt }}\right)$, the MDC-WDP can be measured, as shown in Figure 6.

This model presents the direct effects of moisture content on the $M_{r}$. It will be convenient to estimate $M_{r}$ without requiring more model parameters if the moisture condition is available. However, the matric suction, in its water-related stress state, is not considered. According to the soil water characteristic curve (SWCC), the hysteresis behaviour between matric suction and water content should be incorporated. This may impair the accuracy of the prediction. The model parameters from regression are based on the type of soil, so it may differ from other types of soil. Additionally, as mentioned by the authors, the study was limited to predicting the effect of postcompaction moisture content on $M_{r}$ of one type of soils (i.e., Renfrow). Thus, more studies are needed to extend the scope of application and verify its applicability to other types of soils.

(10) To comprehensively predict the resilient modulus, a new equation was proposed incorporating the effect of net stress and matric suction [27]:

$M_{r}=M_{0}\left(\frac{p}{p_{r}}\right)^{k_{1}}\left(1+\frac{q_{\mathrm{cyc}}}{p_{r}}\right)^{k_{2}}\left(1+\frac{\psi_{m}}{p}\right)^{k_{3}}$,

where $M_{0}$ denotes the resilient modulus at the reference stress state (i.e., $p=p_{r}, q_{\text {cyc }}=p_{r}$, and $\left.\psi_{m}=0\right), p$ is the net mean stress (i.e., $\left(\sigma_{1}+\sigma_{2}+\right.$ $\left.\sigma_{3} / 3\right)-u_{a}$ ), and $p_{r}$ is reference pressure for normalizing $p$, simplified as $1 \mathrm{kPa} ; q_{\mathrm{cyc}}$ is cyclic stress (i.e., the amplitude of variation in deviator stress during cyclic loading-unloading).

This model allows for a smooth transition between the unsaturated state and saturated state of soils. It is derived from the suction-controlled cyclic triaxial 


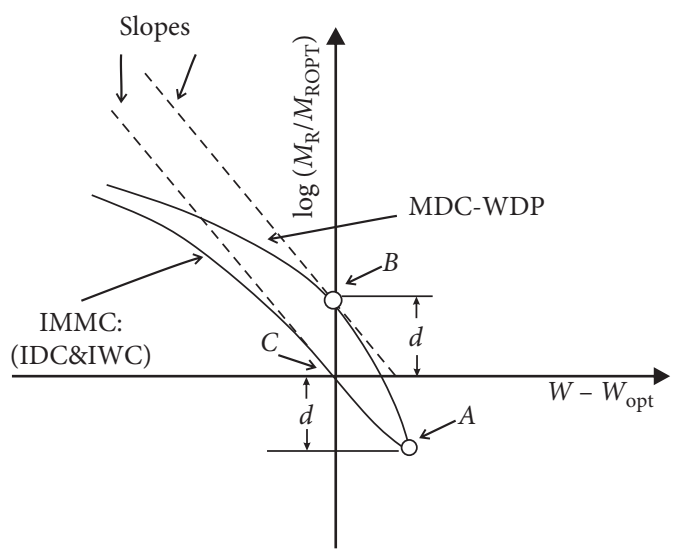

FIGURE 6: Illustration for predicting MWC-WDP (from [23]).

tests, whilst the direct measurement of matric suction for further application will still be complex.

(11) A model for recycled unbound materials was proposed by Azam et al. [75]. This suction-inclusive model incorporated the density ratio to represent the effect of soil density on the resilient modulus. The blend composition was found to significantly affect MDD and OMC of materials. Thus, a new term was added that considered dry density ratio moderated by the effect of RCM content:

$$
\begin{aligned}
M_{r}= & k\left(\frac{\sigma_{m}}{p_{r}}\right)^{k_{1}}\left(\frac{\tau_{\mathrm{oct}}}{\tau_{\text {ref }}}\right)^{k_{2}}\left(\frac{\psi_{m}}{p_{a}}\right)^{k_{3}} \\
& \cdot\left[\frac{\operatorname{DDR}\left(1-\left(k_{4} R C M / 100\right)\right)}{100}\right]^{k_{3}},
\end{aligned}
$$

where $\sigma_{m}$ is mean normal stress (i.e., $\left(\left(\sigma_{1}+\sigma_{2}+\sigma_{3}\right) / 3, \tau_{\text {ref }}\right.$ is reference shear stress (i.e., $\left.\sqrt{2 / 3} q_{f}\right), q_{f}$ is peak shear strength, DDR is dry density ratio (\%), RCM is percent of recycled clay masonry (\%), and $k_{4}$ and $k_{5}$ are regression parameters (factors and exponents).

The previous models mainly focus on the behaviour of subgrade soils and/or virgin aggregates, except for recycled products. The proposed model crushed masonry content, dry density, shear strength, initial matric suction, and stress state. Air entry value will not be needed from SWCC to evaluate the effective stress parameter [75]. The determination of matric suction could make it complex or undermine its accuracy. The applicability to different types of recycled aggregates and general subgrade soils still need further studies.

(12) Han and Vanapalli [76] derived a model to predict the variation of the resilient modulus with respect to the soil suction for compacted fine-grained subgrade soils:

$$
\frac{M_{r}-M_{r, \mathrm{sat}}}{M_{r, \mathrm{opt}}-M_{r, \mathrm{sat}}}=\frac{\psi_{m}}{\psi_{m, \mathrm{opt}}}\left\{\frac{\ln \left[2.718+\left(\psi_{m, \mathrm{opt}} / a\right)^{n}\right]}{\ln \left[2.718+\left(\psi_{m} / a\right)^{n}\right]}\right\}^{m \xi},
$$

where $M_{r \text {,sat }}$ is $M_{r}$ of soil at saturation, $\psi_{\text {opt }}$ is matric suction at OMC, $m, n$, and $\xi$ are model parameters and $\xi$ was found to be equal to 2.0.

It only requires conventional soil properties and alleviates the need for experimental determination of the $M_{r}-\psi$ relationships, while the stress conditions were not incorporated [76]. Compared with models by regression analysis, it is convenient to predict the resilient modulus of subgrade only with soil properties. However, the filter paper method measures matric suction based on previous calibration, and its accuracy is limited. The measurement of matric suction may limit the application of this model.

(13) Considering matric suction, minimum bulk stress, and octahedral shear stress, a new prediction model was proposed by Yao et al. [77]:

$$
M_{r}=k_{0} p_{a}\left(\frac{\psi_{m}}{p_{a}}+1\right)^{k_{1}}\left(\frac{\theta_{m}}{p_{a}}\right)^{k_{2}}\left(\frac{\tau_{\mathrm{oct}}}{p_{a}}+1\right)^{k_{3}} \text {, }
$$

where $\theta_{m}$ is the minimum bulk stress.

This model avoids the issue that the bulk stress exhibited equal values under different combinations of the deviator stress and confining pressure [77]. The relationship between regression coefficients and physical parameters (plasticity index, liquid limit or plastic limit, and percentage passing through the No. $200(0.075 \mathrm{~mm})$ sieve) was established based on completely weathered granite and then verified within A-4 and A-7 soils. Therefore, its applicability to other types of soil still needs further verification.

(14) State variables and stress variables should be taken as model terms, and soil basic properties should be considered in model parameters. Therefore, the matric suction and relative compaction should be incorporated in prediction models of resilient modulus. A new model by Zhang et al. [20] is expressed as

$$
M_{r}=k_{0} p_{a} R C^{k_{1}}\left(\frac{\psi_{m}}{p_{a}}+1\right)^{k_{2}}\left(\frac{\theta_{m}}{p_{a}}\right)^{k_{3}}\left(\frac{\tau_{\text {oct }}}{p_{a}}+1\right)^{k_{4}},
$$

where $R C$ is the relative compaction, defined as the ratio of dry density to $\mathrm{MDD}$, and $k_{0}$ is directly proportional to $M_{r}$.

Compared with the model by Yao et al. [77], the new model considered relative compaction of subgrade. However, it also added an extra parameter to the model. It may take more work to achieve these parameters.

3.3. General Summary. The understanding and knowledge of soil mechanics has been broadened from saturated soils to unsaturated soils. For saturated soils, the resilient modulus models mainly focus on the relationship of $M_{r}$ with the 
stress parameters, i.e., bulk stress, deviator stress, mean normal stress, octahedral shear stress, stress ratio of deviator stress to mean normal stress, and various combination of these stresses. In this way, the problems about soils were simplified and the models performed well in the understanding of the modulus variation with the stress conditions for saturated soils despite the accuracy. However, since the insitu conditions of soils are complicated, especially the seasonal variation of moisture content, it is therefore necessary to develop models to accurately predict the resilient modulus of unsaturated soils. A wide variety of studies have started to pay more attention to unsaturated soils. Based on the previous studies on unsaturated soils, the resilient modulus was related with degree of saturation, moisture content, matric suction, and the mean normal stress. The hysteresis characteristics of the resilient modulus with moisture content were considered. Constitutive models are flexible incorporating various variables that affect $M_{r}$ and are able to achieve reasonably good predictions [13]. Despite the progress in the development of models based on the resilient modulus, limitations lay in the finite soil types and the difficulties in the direct measurement of matric suction during the tests. More studies are needed to extend and/or verify the applicability of the model to various soil types. A model incorporating stress conditions, SWCC, moisture content, and matric suction may be more comprehensive to predict the resilient modulus of unsaturated soils at complicated external conditions. According to the study of Han and Vanapalli [13], most constitutive models of $M_{r}$ incorporating matric suction were modified from the conventional constitutive models, whilst model parameters cannot be directly introduced into the revised models. Direct and precise measurement of matric suction will improve the accuracy of the model on predicting the resilient modulus.

\section{Conclusions}

A selective review about the resilient response of unsaturated soils was presented by incorporating the affecting factors and prediction models. The main points were summarised as follows:

(1) Compared with the resilient modulus models of saturated soils only incorporating stress parameters (i.e., bulk stress, deviator stress, mean normal stress, octahedral shear stress, stress ratio of deviator stress to mean normal stress, and various combination of these stresses), the models of unsaturated soils were more applicable to in-situ conditions considering the moisture content and matric suction besides the stress parameters.

(2) Due to the environmental conditions (e.g., wetting and drying, freezing and thawing, precipitation, and rise in water table), unsaturated soils will be subjected to seasonal variations in moisture content, and consequently, the resilient behaviour will be affected.

(3) The resilient modulus showed an increasing trend with moisture rising to the optimum. However, when it reached its optimum, the values decreased, whilst increasing with the reduction of matric suction.
(4) During the wetting and drying processes, moisture content exhibited a hysteretic behaviour in the relationship with resilient modulus and $M_{r}$ showed higher values for drying cycle at the same moisture content than on the wetting cycle. Under cyclic wetting-drying process, $M_{r}$ could show a downward trend.

(5) Based on the discussion of models based on the resilient modulus derived from different test conditions, it may provide a reference for the future application to the foundation design in various fields of engineering, e.g., road, railway, and airfield.

Considering various models, it will be more beneficial to establish a database including their advantages, limitations, applicability, and conditions that models are derived from. More studies still need to be conducted to verify and extend the applicability of current models to various soil types. Considering the limitations and difficulties about the existing models, mathematical models incorporating stress parameters, SWCC, physical properties, and matric suction may be more comprehensive to predict the resilient modulus of unsaturated soils at complicated external conditions.

\section{Conflicts of Interest}

The author declares that there are no conflicts of interest.

\section{Acknowledgments}

The author would like to thank China Scholarship Council (CSC) and the University of Nottingham for their financial support and Dr Junjian Zhang for his help on figures.

\section{References}

[1] F. Lekarp, U. Isacsson, and A. Dawson, "State of the art. I: resilient response of unbound aggregates," Journal of Transportation Engineering, vol. 126, no. 1, pp. 66-75, 2000.

[2] J. S. Miller and W. Y. Bellinger, Distress Identification Manual for the Long-Term Pavement Performance Program (Fifth Revised Edition), Federal Highway Administration. Office of Infrastructure Research and Development, Washington, DC, USA, 2014.

[3] AASHTO, Standard Specifications for Transportation Materials and Methods of Sampling and Testing, American Association of State Highway and Transportation Officials, Washington, DC, USA, 1986.

[4] S. R. Yang, W. H. Huang, and Y. T. Tai, Variation of Resilient Modulus with Soil Suction for Compacted Subgrade Soils, Transportation Research Record: Journal of the Transportation Research Board, 2005.

[5] H. B. Seed, C. Chan, and C. E. Lee, "Resilience characteristics of subgrade soils and their relation to fatigue failures in asphalt pavements," in International Conference on the Structural Design of Asphalt Pavements, SupplementUniversity of Michigan, Ann Arbor, MI, USA, 1962.

[6] J. Moossazadeh and M. W. Witczak, "Prediction of subgrade moduli for soil that exhibits nonlinear behavior," Transportation Research Record, vol. 810, 1981.

[7] E. C. Drumm, Y. Boateng-Poku, and T. Johnson Pierce, "Estimation of subgrade resilient modulus from standard 
tests," Journal of Geotechnical Engineering, vol. 116, no. 5, pp. 774-789, 1990.

[8] J. Huang, Degradation of Resilient Modulus of Saturated Clay Due to Pore Water Pressure Buildup under Cyclic Loading, The Ohio State University, Columbus, OH, USA, 2001.

[9] C. Monismith, H. B. Seed, F. Mitry, and C. Chan, "Prediction of flexible pavement deflections from laboratory repeatedload tests," NCHRP Report, no. 35, 1967.

[10] J. Uzan, "Characterization of granular material," Transportation Research Record, vol. 1022, no. 1, pp. 52-59, 1985.

[11] P. Kolisoja, Resilient Deformation Characteristics of Granular Materials, Tampere University of Technology Finland, Tampere, Finland, 1997.

[12] D. G. Fredlund and H. Rahardjo, "Soil mechanics principles for highway engineering in arid regions," Transportation Research Record, vol. 1137, pp. 1-11, 1987.

[13] Z. Han and S. K. Vanapalli, "State-of-the-Art: Prediction of resilient Modulus of unsaturated subgrade soils," International Journal of Geomechanics, vol. 16, no. 4, Article ID 04015104, 2016.

[14] N. Thom, Principles of Pavement Engineering, Thomas Telford Ltd., London, UK, 2008.

[15] E. C. Drumm, J. S. Reeves, M. R. Madgett, and W. D. Trolinger, "Subgrade resilient modulus correction for saturation effects," Journal of Geotechnical and Geoenvironmental Engineering, vol. 123, no. 7, pp. 663-670, 1997.

[16] N. Khoury and M. Zaman, "Correlation between resilient modulus, moisture variation, and soil suction for subgrade soils," Journal of the Transportation Research Board, vol. 1874, pp. 99-107, 2004.

[17] S.-R. Yang, H.-D. Lin, J. H. S. Kung, and W.-H. Huang, "suction-controlled laboratory test on resilient modulus of unsaturated compacted subgrade soils," Journal of Geotechnical and Geoenvironmental Engineering, vol. 134, no. 9, pp. 1375-1384, 2008.

[18] N. Khoury, R. Brooks, and C. Khoury, "Environmental influences on the engineering behavior of unsaturated undisturbed subgrade soils: effect of soil suctions on resilient modulus," International Journal of Geotechnical Engineering, vol. 3, no. 2, pp. 303-311, 2009.

[19] K. Ng, Z. R. Henrichs, K. Ksaibati, and S. S. Wulff, "Resilient modulus of subgrade materials for mechanistic-empirical pavement design guide," Road Materials and Pavement Design, vol. 19, no. 7, pp. 1523-1545, 2018.

[20] J. Zhang, J. Peng, W. Liu, and W. Lu, "Predicting resilient modulus of fine-grained subgrade soils considering relative compaction and matric suction," Road Materials and Pavement Design, pp. 1-13, 2019.

[21] M. Zaman and N. Khoury, "Effect of soil suction and moisture on resilient modulus of subgrade soils in Oklahoma," 2007.

[22] C. Khoury, N. Khoury, and G. Miller, "Effect of cyclic suction history (hydraulic hysteresis) on resilient modulus of unsaturated fine-grained soil," Journal of the Transportation Research Board, no. 2232, pp. 68-75, 2011.

[23] N. Khoury, R. Brooks, C. Khoury, and D. Yada, "Modeling resilient modulus hysteretic behavior with moisture variation," International Journal of Geomechanics, vol. 12, no. 5, pp. 519-527, 2012.

[24] N. Khoury, R. Brooks, S. Y. Boeni, and D. Yada, "Variation of resilient modulus, strength, and modulus of elasticity of stabilized soils with postcompaction moisture contents," Journal of Materials in Civil Engineering, vol. 25, no. 2, pp. 160-166, 2013.
[25] D. Li and E. T. Selig, "Cumulative plastic deformation for finegrained subgrade soils," Journal of Geotechnical Engineering, vol. 122, no. 12, pp. 1006-1013, 1996.

[26] G. A. Miller, S. Y. Teh, D. Li, and M. M. Zaman, "Cyclic shear strength of soft railroad subgrade," Journal of Geotechnical and Geoenvironmental Engineering, vol. 126, no. 2, pp. 139-147, 2000.

[27] C. W. W. Ng, C. Zhou, Q. Yuan, and J. Xu, "Resilient modulus of unsaturated subgrade soil: experimental and theoretical investigations," Canadian Geotechnical Journal, vol. 50, no. 2, pp. 223-232, 2013.

[28] J. M. Rasul, G. S. Ghataora, and M. P. N. Burrow, "The effect of wetting and drying on the performance of stabilized subgrade soils," Transportation Geotechnics, vol. 50, pp. 223-232, 2017.

[29] J. Krahn and D. G. Fredlund, "On total, matric and osmotic suction,” Soil Science, vol. 114, no. 5, pp. 339-348, 1972.

[30] T. B. Edil and S. E. Motan, "Laboratory evaluation of soil suction components," Geotechnical Testing Journal, vol. 7, no. 4, pp. 173-181, 1984.

[31] D. G. Fredlund, H. Rahardjo, and M. D. Fredlund, Unsaturated Soil Mechanics in Engineering Practice, John Wiley \& Sons, Hoboken, NJ, USA, 2012.

[32] D. Li and E. T. Selig, "Resilient modulus for fine-grained subgrade soils," Journal of Geotechnical Engineering, vol. 120, no. 6, pp. 939-957, 1994.

[33] D.-S. Kim, W.-S. Seo, and M.-J. Kim, "Deformation characteristics of soils with variations of capillary pressure and water content," Soils and Foundations, vol. 43, no. 4, pp. 71-79, 2003.

[34] M. Nuth and L. Laloui, "Unified stress framework for modelling unsaturated subsoil behaviour," Road Materials and Pavement Design, vol. 8, no. 4, pp. 767-781, 2007.

[35] A. Dawson, Water in Road Structures: Movement, Drainage \& Effects, Vol. Vol. 5, Springer Science \& Business Media, Berlin, Germany, 2008.

[36] O. Coronado, B. Caicedo, S. Taibi, A. Gomes Correia, H. Souli, and J.-M. Fleureau, "Effect of water content on the resilient behavior of non standard unbound granular materials," Transportation Geotechnics, vol. 7, pp. 29-39, 2016.

[37] A. Dawson, N. Thom, and J. Paute, Mechanical Characteristics of Unbound Granular Materials as a Function of Condition, pp. 35-44, 1996.

[38] R. Ji and T. Nantung, "Quantification of benefits of subsurface drainage on pavement performance in Indiana," in Proceedings of the Transportation Research Board 94th Annual Meeting, Transportation Research Board, Washington DC, USA, Washington DC, USA, January 2015.

[39] T. Saevarsdottir and S. Erlingsson, "Water impact on the behaviour of flexible pavement structures in an accelerated test," Road Materials and Pavement Design, vol. 14, no. 2, pp. 256-277, 2013.

[40] I. L. M. Sabri, "Study on the impact of moisture content on subgrade strength," in Proceedings of the 5th International Symposium 2015, SEUSL, London, UK, June 2015.

[41] M. S. Rahman and S. Erlingsson, "Moisture influence on the resilient deformation behaviour of unbound granular materials," International Journal of Pavement Engineering, vol. 17, no. 9, pp. 763-775, 2016.

[42] T. F. Yideti, B. Birgisson, D. Jelagin, and A. Guarin, "Packing theory-based framework for evaluating resilient modulus of unbound granular materials," International Journal of Pavement Engineering, vol. 15, no. 8, pp. 689-697, 2014.

[43] M. M. Allam and A. Sridharan, "Effect of wetting and drying on shear strength," Journal of the Soil Mechanics and Foundations Division, vol. 107, no. 4, pp. 421-438, 1981. 
[44] Y. Guney, D. Sari, M. Cetin, and M. Tuncan, "Impact of cyclic wetting-drying on swelling behavior of lime-stabilized soil," Building and Environment, vol. 42, no. 2, pp. 681-688, 2007.

[45] R. Chen and C. W. W. Ng, "Impact of wetting-drying cycles on hydro-mechanical behavior of an unsaturated compacted clay," Applied Clay Science, vol. 86, pp. 38-46, 2013.

[46] A. M. Tang, M. N. Vu, and Y.-J. Cui, "Effects of the maximum soil aggregates size and cyclic wetting-drying on the stiffness of a lime-treated clayey soil," Géotechnique, vol. 61, no. 5, pp. 421-429, 2011.

[47] M. M. Zaman, J.-H. Zhu, and J. G. Laguros, "Durability effects on resilient moduli of stabilized aggregate base," Transportation Research Record: Journal of the Transportation Research Board, vol. 1687, no. 1, pp. 29-38, 1999.

[48] A. J. Ceratti, W. Y. Y. Gehling, and W. P. Núñez, "Seasonal variations of a subgrade soil resilient modulus in southern Brazil," Transportation Research Record, vol. 1874, no. 1, pp. 165-173, 2004.

[49] D. Fredlund and S. Vanapalli, "Shear strength of unsaturated soils," Methods of Soil Analysis: Part, vol. 4, pp. 329-361, 2002.

[50] D. Sheng, D. G. Fredlund, and A. Gens, "A new modelling approach for unsaturated soils using independent stress variables," Canadian Geotechnical Journal, vol. 45, no. 4, pp. 511-534, 2008.

[51] E.-C. Leong and H. Abuel-Naga, "Contribution of osmotic suction to shear strength of unsaturated high plasticity silty soil," Geomechanics for Energy and the Environment, vol. 15, pp. 65-534, 2017.

[52] S. J. Wheeler and V. Sivakumar, "An elasto-plastic critical state framework for unsaturated soil," Géotechnique, vol. 45, no. 1, pp. 35-53, 1995.

[53] D. Gallipoli, S. J. Wheeler, and M. Karstunen, "Modelling the variation of degree of saturation in a deformable unsaturated soil," Géotechnique, vol. 53, no. 1, pp. 105-112, 2003.

[54] X. S. Li, "Effective stress in unsaturated soil: a microstructural analysis," Géotechnique, vol. 53, no. 2, pp. 273-277, 2003.

[55] C. E. Cary and C. E. Zapata, "Resilient modulus for unsaturated unbound materials," Road Materials and Pavement Design, vol. 12, no. 3, pp. 615-638, 2011.

[56] S. K. Vanapalli, D. G. Fredlund, D. E. Pufahl, and A. W. Clifton, "Model for the prediction of shear strength with respect to soil suction," Canadian Geotechnical Journal, vol. 33, no. 3, pp. 379-392, 1996.

[57] K. " Terzaghi, Theoretical Soil Mechanics, Chapman And Hall, Limited, London, UK, 1943.

[58] A. W. Bishop, "The principle of effective stress," Teknisk Ukeblad, vol. 39, pp. 859-863, 1959.

[59] N. Khalili and M. Khabbaz, "A unique relationship of chi for the determination of the shear strength of unsaturated soils," Geotechnique, vol. 48, no. 5, 1998.

[60] J. D. Coleman, "Correspondence," Géotechnique, vol. 12, no. 4, pp. 348-350, 1962.

[61] D. G. Fredlund and N. R. Morgenstern, "Stress state variables for unsaturated soils," Journal of Geotechnical and Geoenvironmental Engineering, vol. 103, 1977.

[62] J. E. B. Jennings and J. B. Burland, "Limitations to the use of effective stresses in partly saturated soils," Géotechnique, vol. 12, no. 2, pp. 125-144, 1962.

[63] W. Dunlap, A Report on a Mathematical Model Describing the Deformation, Texas Transportation Institute, Texas A\&M University, College Station, TX, USA, 1963.

[64] R. F. Pezo, "A general method of reporting resilient modulus tests of soils, a pavement engineer's point of view," in
Proceedings of the 72nd Annual Meeting of the TRB, Washington, DC, USA, January 1993.

[65] N. Garg and M. R. Thompson, "Triaxial characterization of Minnesota road research project granular materials," Transportation Research Record: Journal of the Transportation Research Board, vol. 1577, no. 1, pp. 27-36, 1997.

[66] W. Tam and S. Brown, "Back-analyzed elastic stiffnesses: comparison between different evaluation procedures," in Nondestructive Testing of Pavements and Backcalculation of Moduli, ASTM International, West Conshohocken, PA, USA, 1989.

[67] R. G. Hicks and C. L. Monismith, "Factors influencing the resilient response of granular materials," Highway Research Record, vol. 345, pp. 15-31, 1971.

[68] M. Karasahin, A. Dawson, and J. Holden, "Applicability of resilient constitutive models of granular material for unbound base layers," Transportation research record, vol. 1406, 1993.

[69] J. W. Pappin, Characteristics of a Granular Material for Pavement Analysis, University of Nottingham, Nottingham, UK, 1979.

[70] H. Boyce, "A nonlinear model for the elastic behaviour of granular materials under repeated loading"," in Proceedings of the International Symposium on Soils under Cyclic and Transient Loading, Balkema PubI, Swansea, Wales, January 1980.

[71] M. Witczak and J. Uzan, The Universal Airport Design System, Report I of IV: Granular Material Characterization, Department of Civil Engineering, University of Maryland, College Park, MD, USA, 1988.

[72] B. Santha, "Resilient modulus of subgrade soils: comparison of two constitutive equations," Transportation research record, vol. 1462, 1994.

[73] ARA, Guide for Mechanistic-Empirical Design of New and Rehabilitated Pavement Structures, Transportation Research Board of the National Academies, Washington, DC, USA, 2004.

[74] R. Y. Liang, S. Rabab'ah, and M. Khasawneh, "Predicting moisture-dependent resilient modulus of cohesive soils using soil suction concept," Journal of Transportation Engineering, vol. 134, no. 1, pp. 34-40, 2008.

[75] A. M. Azam, D. A. Cameron, and M. M. Rahman, "Permanent strain of unsaturated unbound granular materials from construction and demolition waste," Journal of Materials in Civil Engineering, vol. 27, no. 3, Article ID 04014125, 2015.

[76] Z. Han and S. K. Vanapalli, "Model for predicting resilient modulus of unsaturated subgrade soil using soil-water characteristic curve," Canadian Geotechnical Journal, vol. 52, no. 10, pp. 1605-1619, 2015.

[77] Y. Yao, J. Zheng, J. Zhang, J. Peng, and J. Li, "Model for predicting resilient modulus of unsaturated subgrade soils in South China," KSCE Journal of Civil Engineering, vol. 22, no. 6, pp. 2089-2098, 2018. 